\title{
ZONA DE MONUMENTOS HISTÓRICOS SANTIAGO DE QUERÉTARO. UNA EXPERIENCIA DE GESTIÓN DEL PATRIMONIO CULTURAL EN MÉXICO ${ }^{* *}$
}

\author{
ZONE OF HISTORICAL MONUMENTS SANTIAGO DE QUERÉTARO. AN EXPERIENCE OF \\ CULTURAL HERITAGE MANAGEMENT IN MEXICO
}

\author{
PLINIO GUILLÉN ALARCÓN ${ }^{(*)}$ \\ Fecha de recepción: 02 de setiembre de 2017 \\ Fecha de aprobación: 21 de febrero de 2018
}

\begin{abstract}
RESUMEN
La Zona de Monumentos Históricos Santiago de Querétaro (ZMHQ) es uno de los 10 centros históricos de México que ha sido inscrito en la lista de Patrimonio Mundial de la UNESCO. Esta inscripción se logró a partir del desarrollo de un grupo de proyectos que buscaban la recuperación y conservación de este espacio, el cual contiene las huellas de una serie de hechos históricos relevantes en la formación de los Estados Unidos de México. En el marco de este proceso, con el aliciente de la nominación como Patrimonio Mundial, se hizo evidente la necesidad de una herramienta de gestión integral que permita la protección o, mejor aún, la revitalización de la ZMHQ. Sin embargo, la revisión de la bibliografía relacionada ha permitido concluir que este objetivo aún no ha sido alcanzado, a pesar de existir un marco normativo y de gestión que se ha desarrollado en los tres niveles de gobierno mexicano (federal, estatal y municipal). Las experiencias positivas y negativas para la gestión de la ZMHQ que han tenido lugar hasta ahora deben permitir rescatar una serie de aspectos importantes de gestión, que luego puedan servir para realizar evaluaciones en otros ámbitos territoriales, como el peruano.
\end{abstract}

PALABRAS CLAVE

Gestión del patrimonio, centros históricos, México, Querétaro

\section{ABSTRACT}

The Historic Monuments Zone of Santiago de Querétaro (ZMHQ) is one of the 10 Mexican historical centers that has been inscribed into the World Heritage list of UNESCO. This inscription was achieved thanks to the development of a series of projects that looked for the recovery and preservation of this zone, which contains the traces of a series of relevant historical facts in the formation of the United States of Mexico. Within this process, and the incentive of the nomination as World Heritage, the need of comprehensive management tool that would allow for the protection of the ZMHQ became evident, or, more so, for the revitalization of this zone. However, the bibliographical review concludes that this objective has not been achieved, despite the existence of a normative and management framework, which was developed in the three levels of Mexican government (Federal, National and Municipal). The positive and negative experiences the management of the ZMHQ should allow us to rescue a series of important aspects of management. These could be useful later on, to carry out evaluations in other territorial settings, such as Peru.

\section{KEYWORDS}

Heritage management, historic center, Mexico, Querétaro

(*) El presente artículo fue elaborado a partir de un trabajo previo, titulado Zona de Monumentos Históricos de Santiago de Querétaro. Una Experiencia de Gestión Cultural en México, planteado en el seminario Rehabilitación, Revitalización y Gestión de las Ciudades Históricas (ciclo 2017-I), dictado por el MSc. Arq. José Hayakawa Casas en la Maestría de Gestión del Patrimonio Cultural de la Unidad de Posgrado de Ciencia Sociales de la Universidad Nacional Mayor de San Marcos (UNMSM).

$\left.{ }^{(* *}\right)$ Licenciado en Arqueología por la UNMSM. Con estudios en la Maestría de Gestión del Patrimonio Cultural de la Unidad de Posgrado de Ciencia Sociales de la misma universidad. Jefe de campo de la sede Caral - Zona Arqueológica Caral. Contacto: plinioga@hotmail.com 


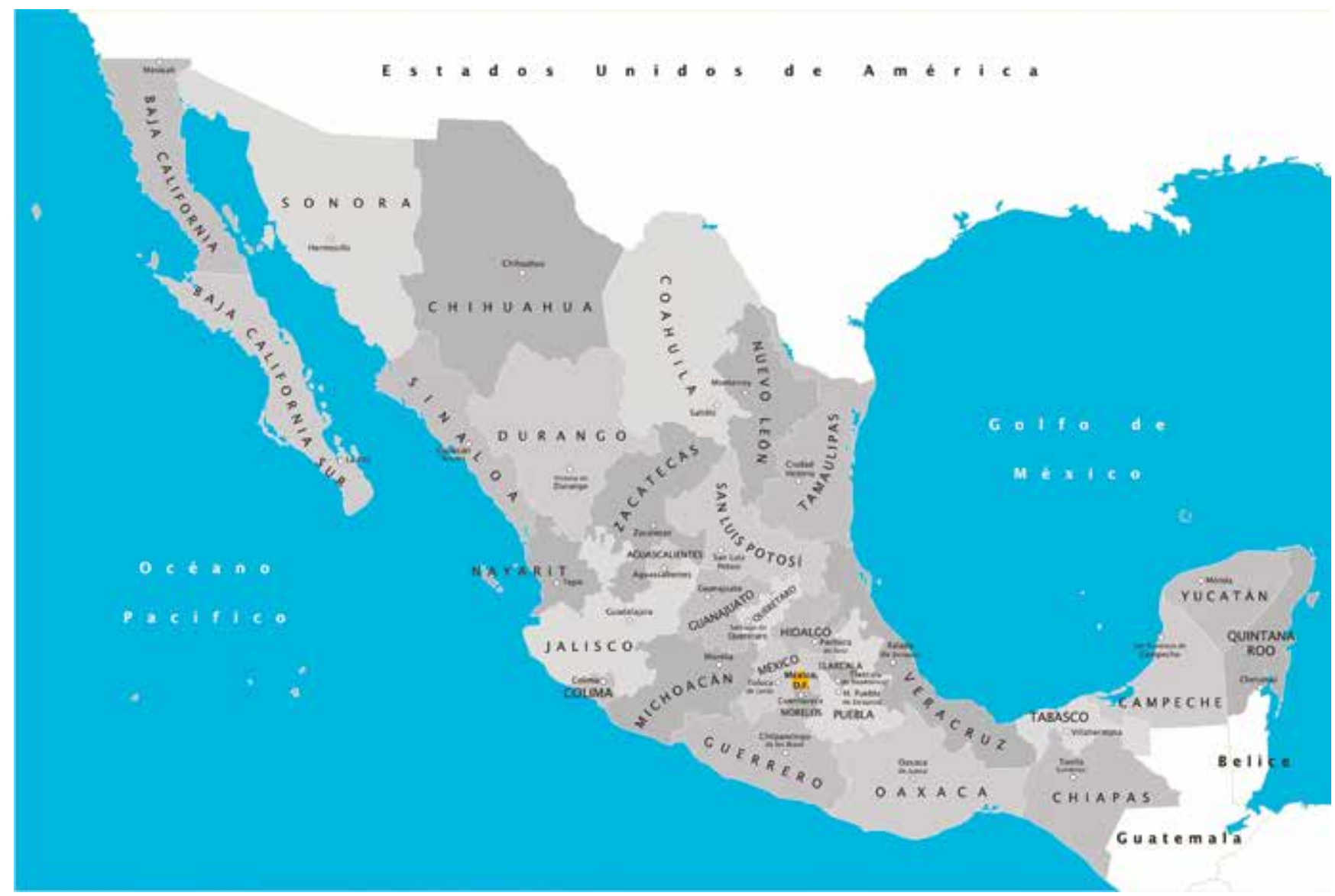

Figura 1. Estados de la República Federal de México en la actualidad. Recuperado de https://es.wikipedia. org/wiki/Organizaci\%C3\%B3n_territorial_de_M\%C3\%A9xico\#/media/File:Mapa_De_Mexico_2009.png
La República de México tiene tres características: es democrática, representativa y federal. Esto último implica la existencia de 31 estados libres (o entidades federativas), los cuales tienen su propio gobierno y leyes, además de un territorio y población definidos (Figura 1). A esta jurisdicción se suma el Distrito Federal, que es la sede del Gobierno federal. En conjunto, conforman una federación de estados regidos por las leyes de la Constitución Política de 1917. En el caso de los estados, cabe indicar que cada uno es autónomo: el gobernador y los diputados locales son elegidos por su población. También presentan su propia constitución, aunque esta no puede contraponerse a la constitución de la República. Así, cada estado tiene su capital y está dividido internamente en municipios, gobernados cada uno por un respectivo ayuntamiento, del cual es responsable el presidente municipal y los representantes del Cabildo elegidos por la población correspondiente.

México presenta un territorio muy diverso, que sirvió en el pasado como soporte para el establecimiento de distintos grupos culturales en los que se dividieron los primeros pobladores de América. Durante el periodo prehispánico se desarrollaron una serie de sociedades que dejaron una importante herencia cultural (Rivera Dorado \& Vidal Lorenzo, 1994), la cual posteriormente se convertiría en la base de la construcción de la identidad nacional mexicana. Asimismo, la llegada de los españoles dio lugar a una nueva interacción que devino en el denominado "mestizaje cultural", a pesar del intento de los conquistadores de borrar por completo todo tipo de referencia a la idiosincrasia de las poblaciones mexicanas prehispánicas. Luego, tras la Independencia y establecimiento de la República, las diferencias sociales fueron acrecentándose cada vez más, lo cual generó una serie de movimientos políticos y sociales que desde 


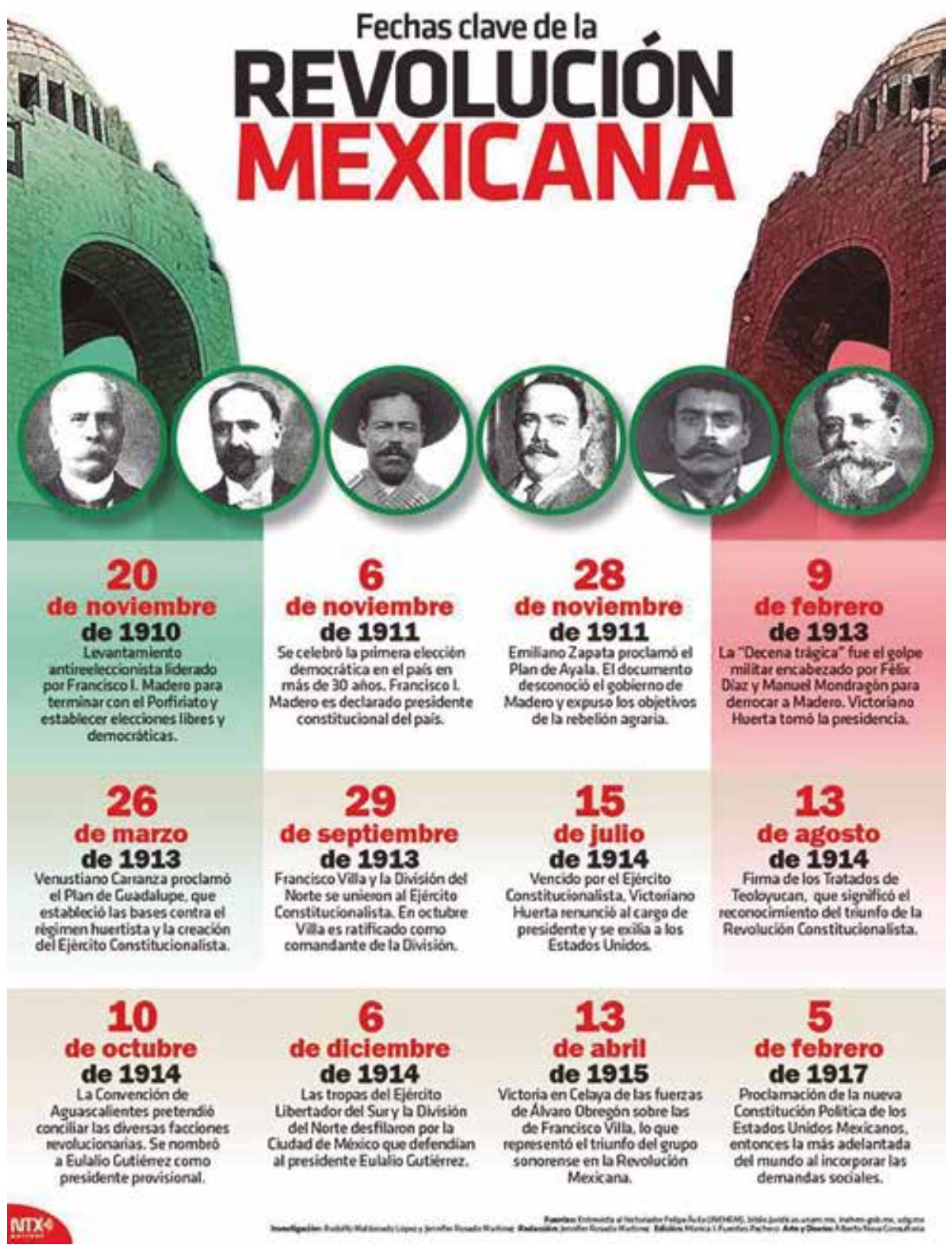

la Historia suelen abarcarse bajo el concepto de Revolución mexicana (Figura 2). Una de las implicancias de dicho proceso de insurgencia fue el reconocimiento de la importancia del aspecto cultural, lo cual se vio reflejado en la búsqueda de referentes identitarios, y el interés por las construcciones $\mathrm{y} / \mathrm{o}$ costumbres que fueron reconocidas inicialmente por su belleza y monumentalidad'. Así, este interés por el ámbito cultural influenció en la construcción de la nación, cuya máxima expresión es quizá la Constitución de 1917, que fue la primera en América en incluir derechos sociales
Figura 2. Fechas clave de la Revolución mexicana. Recuperado de https://candidmanmx.wordpress. com/2015/11/20/infografia-fechas-clave-de-la-revolucion-mexicana/

1. En el gobierno de Victoriano Huerta (1913-1914) se promulgó la Ley sobre Conservación de Monumentos Históricos y Artísticos y Belleza Naturales (1914). Sin embargo, anteriormente ya se habían promulgado dos leyes importantes: Ley sobre Monumentos Arqueológicos (1897) y Ley de Bienes Inmuebles de la Nación (1902) (Gonzáles Gómez \& Hiernaux Nicolás, 2015, pp. 277-283). 
que buscaban reconocer la igualdad y la libertad a los ciudadanos, por lo que esta revolución significó un antes y un después para México (Schiavon, Spenser \& Vásquez Olivera, 2007; Gómez-Huerta, 2006).

Por otro lado, la geopolítica contemporánea de este país está definida principalmente por su cercanía con los EE.UU., y por los vínculos que se han generado entre ambos países, bajo la supremacía del segundo (Rocha, 2016). Ejemplo de esto fue el Consenso de Washington (1989), a partir del cual se establecieron políticas neoliberales, que determinarían el establecimiento de una serie de convenios y tratados comerciales entre ambos países, así como con otros países de Latinoamérica y Europa. Estos acuerdos permitieron a México tomar una posición económica preponderante respecto de otros países de la región y de Sudamérica, sobre el importante pilar que es su cultura (Colegio de Bachilleres del Estado de Sonora, 2015, pp. 93-103).

\section{Apuntes sobre cultura y urbanismo en México}

A consecuencia de la Revolución mexicana y el cambio de Constitución de 1917, en México se inició un proceso de cambios culturales que tuvo su base en el sentir nacionalista, orientado a reivindicar a la mayoría de grupos sociales que durante largo tiempo habían ocupado una posición marginada y postergada. La creación de la Secretaria de Educación Pública (SEP, 1921), fue un gran paso para la formulación de las primeras propuestas de políticas culturales, aunque en primera instancia respondieron a los intereses del gobierno de turno. En las dos décadas siguientes, los años 30 y 40 , se fundaron otras instituciones: el Fondo de Cultura Económica (1934), el Instituto Nacional de Antropología e Historia (INAH, 1939), la Secretaría de Cultura de México (1942), el Instituto Nacional de Bellas Artes (INBA, 1946) y el Instituto Nacional Indigenista (1948); los cuales fueron incluidos en los programas que el Estado estaba asumiendo como parte de sus políticas culturales. En la década del 50, la televisión y los medios de comunicación mexicanos alcanzan su mayor auge, la denominada "época de oro" del cine mexicano. Hacia la década del 70, cambia la visión de la cultura como unívoca y estática, y se reconoce el carácter plural y diverso de México, que por lo tanto se encontraba atravesando constantes cambios. Esto significó el inicio de un viraje en los paradigmas de los estudios culturales, que incidiría en una mayor presencia del Estado y la consolidación de las futuras políticas culturales (Rodríguez Barba, 2008, p. 16). En la década siguiente, en los años 80, se llevó a cabo en México la Conferencia Mundial sobre Políticas Culturales de la UNESCO, donde se expuso la necesidad de que "Ios países actualizaran sus legislaciones en la materia, y se recomendó la descentralización de las estructuras de promoción cultural y la inclusión de los diversos actores sociales en el diseño de las políticas culturales" (Rodríguez Barba, 2008, p. 17).

Así, México inició su inserción en los ámbitos internacionales a nivel cultural, lo cual dio lugar a la creación en 1988 del Consejo Nacional para la Cultura y las Artes (CONACULTA). Este consejo se convirtió en el organismo rector de la cultura en México, complementado por el Fondo Nacional para las Culturas y las Artes (FONCA), que tiene como objetivo promover la creación artística, lo cual incluye la entrega de becas y estímulos. Sin embargo, ambas instituciones presentan aún problemas significativos en distintos ámbitos:

Presupuesto (aún depende de la SEP²), Constitución (no cuenta con el grupo humano necesario), Dirigencia (el titular lo nombra directamente el Presidente de la República), Carácter Jurídico (no cuenta con un estatuto jurídico que le dé legalidad y capacidad organizativa), la coordinación de sus instancias de acción (no existe coherencia en sus líneas de acción y programas, siendo determinados muchas veces por el gobierno de turno), la claridad de los recursos (no

\footnotetext{
2. Secretaria de Educación Pública
} 
existe una rendición transparente) y el monto de los recursos presupuestales (cultura tiene un presupuesto insuficiente que no se acerca al 1\% del PBI recomendado por la UNESCO). (Ejea Mendoza, 2008, pp. 5-6)

El interés por la cultura nacional permitió establecer los términos legales para la protección del patrimonio cultural del país. Por ejemplo, fue promulgada la Ley General de Bienes Nacionales (1969), que declara de dominio de la nación a distintos bienes culturales (monumentos arqueológicos, artísticos e históricos, manuscritos, libros, entre otros). Para aplicar esta ley y otras que se emitieron progresivamente, se comisionó a la Secretaria de Educación Pública, y a la Secretaria de Patrimonio y Fomento Industrial. En esa misma línea fueron promulgadas la Ley Federal del Patrimonio Cultural de la Nación (1970), y la Ley Federal sobre Monumentos y Zonas Arqueológicas, Artísticos e Históricos (1972), para cuya aplicación se sumaron el Instituto Nacional de Antropología e Historia (INAH), y el Instituto de Bellas Artes y Literatura (1946). Además, de estos institutos dependen también el Registro Público de Monumentos y Zonas Arqueológicas e Históricas, y el Registro Público de Monumentos Artísticos. Para formar parte de este registro, los monumentos deben ser inscritos en el Registro Público de la Propiedad de acuerdo a su jurisdicción, de forma que puedan ser declarados como propiedad de la nación (Gonzáles Gómez \& Hiernaux Nicolás, 2015).

La preocupación por establecer políticas urbanas se inició también inmediatamente después de la Revolución mexicana: México dejó de ser un país rural para convertirse en uno urbano-industrial, centralizado en la Ciudad de México, una constante hasta el día de hoy. Por esa razón, desde un principio los gobiernos se preocuparon por la descentralización de la economía, y buscaron promover el incremento de la industria en otras regiones, fuera de la ciudad. Con ello se esperaba generar condiciones adecuadas para que las poblaciones se mantuvieran en sus tierras y retomasen el interés del Estado por la recuperación de la economía rural. Para llevar a cabo las primeras acciones en pos de ese objetivo se buscó establecer un marco legal, el cual sentaría las bases de las políticas urbanas, que se desarrollaron en dos etapas: la primera, de 1915 a 1940; y la segunda, de 1940 a 1970. Sin embargo, el interés por el desarrollo industrial, que se manifestó en la creación de parques y ciudades industriales, fue contraproducente, porque generó mayores desigualdades $y$, en el ámbito territorial, no solo no redujo sino que incrementó el centralismo. Posteriormente, se promulgó la Ley de Desarrollo Urbano del Distrito Federal (1975), que buscaba regular el crecimiento en relación a un nuevo orden urbano, para lo cual fue elaborado el Plan Director de Desarrollo Urbano del Distrito Federal. Además, se estableció la Ley General de Asentamientos Humanos (1976), que se convirtió en la base legal sobre la cual se desarrollaron las siguientes planificaciones urbanas (Villareal, 1986). Al respecto, más adelante se realizarán anotaciones específicas.

\section{Centros históricos en México}

Las primeras ciudades planificadas en el continente americano según el esquema ajedrezado fueron establecidas en 1501 por el gobernador Nicolás de Ovando y Cáceres (1501-1509), entre ellas la ciudad de Santo Domingo (en la actual República Dominicana). Así, dicho esquema continuaría en el marco del interés del gobierno español respecto a la planificación y el trazado urbano en México, así como en muchas otras colonias de América.

Por otro lado, es posible indicar que las primeras acciones por valorar los centros históricos corresponden a las ordenanzas reales de Felipe II (1573), en las cuales se considera a estos espacios producto de un sincretismo cultural entre los pueblos locales (América Latina y El Caribe) y los modelos europeos. En estas ordenanzas se establece que "plazas, calles y solares debían ser trazados en línea recta, para lo cual había que comenzar con la delimitación de la plaza principal, o plaza mayor, y a partir de allí 
devenir Vol. 5, N9, ENERO - JUNIO 2018, PP. 117-136 - EstudIOS I ISSN 2312-7562 | E-ISSN 2616-4949

UNIVERSIDAD NACIONAL DE INGENIERÍA, LIMA

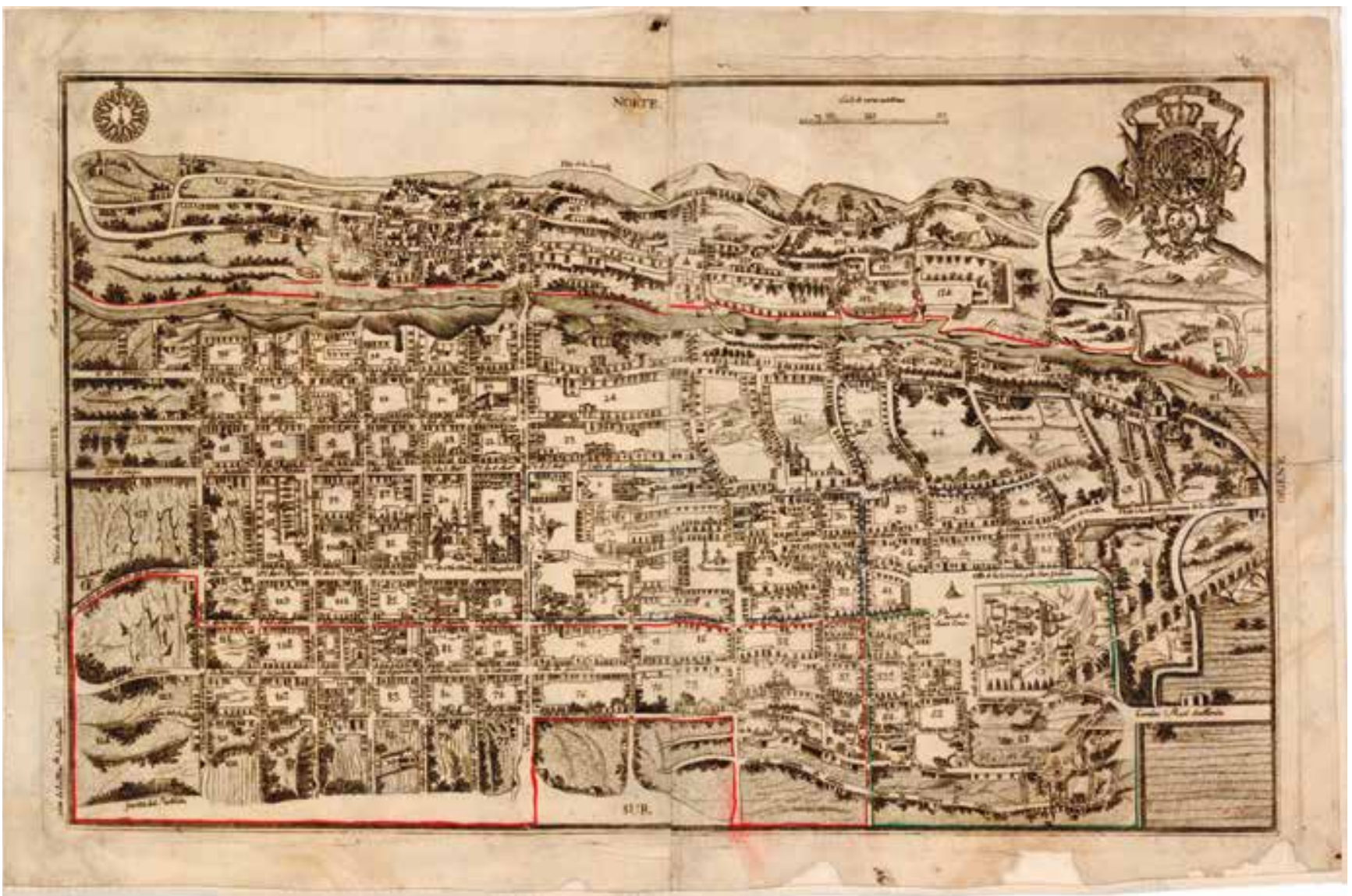

Figura 3. Plano de Querétaro, 1796 [Grabado elaborado en cobre por Ruíz Calado]. En Arte Colonial. Catálogo razonado de artistas coloniales de Latinoamérica. Recuperado de https://artecolonial.wordpress.com/2011/04/25/ plano-de-queretaro-mexico-1796/ construir la red de calles" (Sánchez López, 2000, párr. 22). Una vez declarada la Independencia (1821), surgió una nueva corriente nacionalista, dirigida por mestizos, que dio lugar a un interés por elementos culturales que representasen ese sentimiento, que implicaba el reconocimiento de un pasado prehispánico, que luego trascendería en movimientos indígenas (Figura 3).

Este interés por elementos culturales representativos de esta corriente nacionalista se acentuó durante el segundo régimen de Porfirio Díaz (1884-1911), que otorgó apoyo a estudios arqueológicos, con el cual se concretó la primera recuperación de los monumentos arquitectónicos construidos durante la ocupación española. Si bien estos monumentos estuvieron asociados directamente a la Colonia, fueron valorados por la impronta de mestizaje que algunos de estos presentaban, así como por el ingenio humano allí materializado. Así, se desarrollaron iniciativas para conservarlos, en tanto patrimonio cultural: se generaron las primeras propuestas normativas (leyes 1930 y 1934) para su protección y conservación, que tuvieron como resultado la creación del INAH. En esta línea, en 1952 fue creada la Secretaría de Bienes Nacionales (actualmente Secretaría de Desarrollo Urbano y Ecología), que tuvo como objetivo realizar el inventario de los bienes patrimoniales nacionales.

Posteriormente, la Carta de Venecia (1964) marcaría el primer interés formal internacional por la preservación de los centros históricos; asimismo, en la Convención del Patrimonio Mundial (1972) fue retomada esta iniciativa. Sin embargo, es en la Carta del Restauro (1972) donde se desarrollaron las directrices para conservar, intervenir y preservar este patrimonio (anexo D, "La Tutela de los Centros Históricos"). En el caso de México, es en 1984 que se firma la Convención del Patrimonio Mundial, momento 


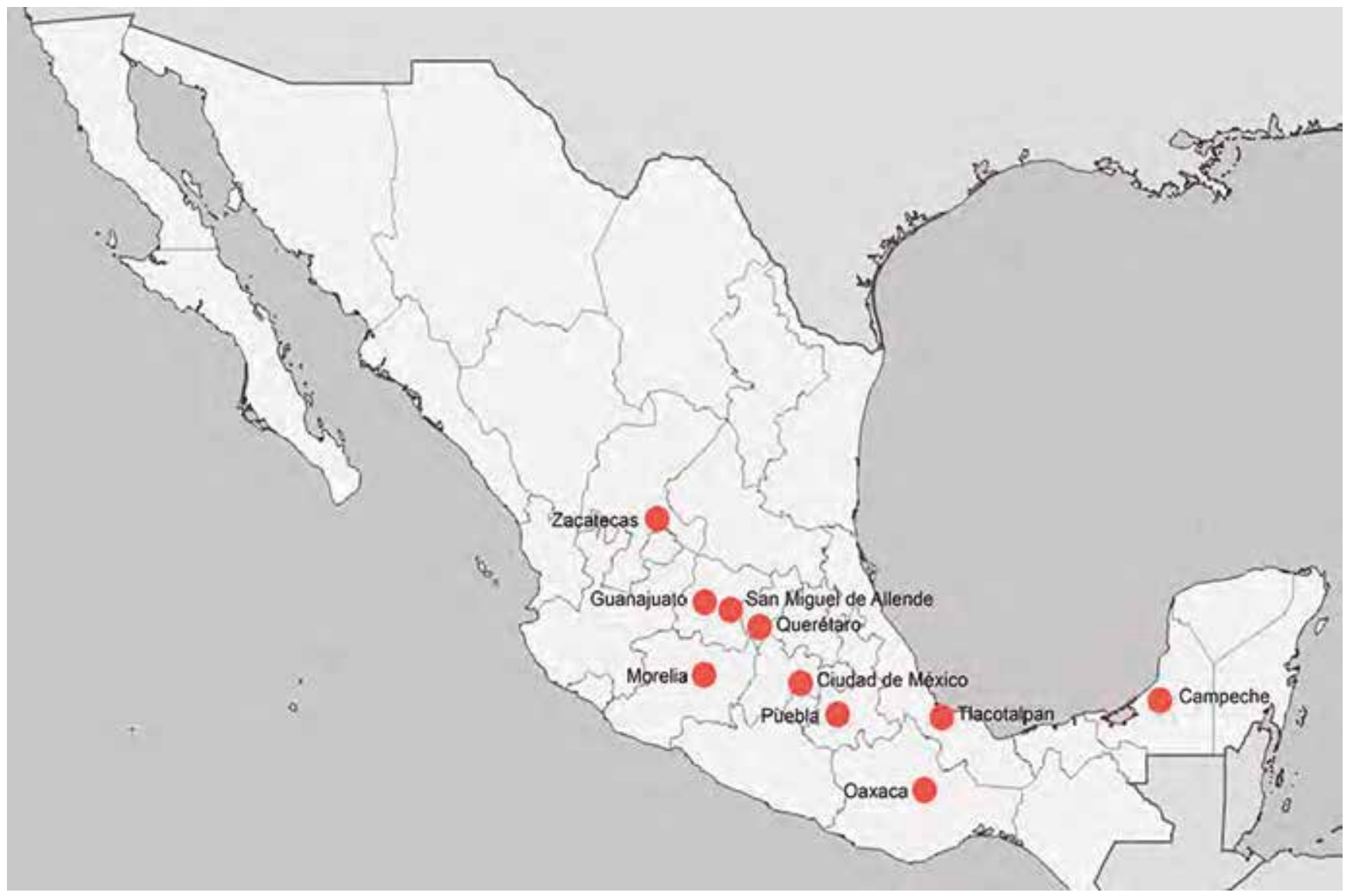

en que cuenta con 31 sitios inscritos, entre ellos 10 centros históricos (Figura 4). Hacia 1996 la convención requirió la implementación de planes de manejo: entonces Ciudad de México, Querétaro y San Miguel de Allende eran los únicos que contaban con esta herramienta. En 2000 México firmó la Declaración de la Ciudad de México, que contempla la elaboración de un plan maestro de programas especiales para orientar las intervenciones en los centros históricos (Gómez Porter, 2013).

Con la implementación en 2010 de la "Guía Metodológica para la Formulación, Seguimiento y Evaluación de Planes de Manejo para las Ciudades Mexicanas Patrimonio de la Humanidad y los Centros Históricos y Tradicionales del País" por parte de la Secretaría de Desarrollo Social (SEDESOL), cambiaron los procesos de elaboración y diseño de los planes de manejo, ya que esta guía contemplaba la "elaboración y el diseño de planes de manejo en los centros históricos nacionales, según las variantes locales, tales como legislaciones estatales y municipales, y su implicación en el diseño de políticas urbanas" (Gómez Porter, 2013, p. 191). Un aspecto crucial que señala esta guía es la inclusión de la comunidad local por medio de talleres de participación ciudadana, orientados a involucrar a todos los actores y sectores necesarios.

En el caso del INAH, se buscó mejorar y afianzar los procesos de planeación, para lo que se elaboró el Programa de Trabajo 2007-2012, que buscaba el "fortalecimiento del modelo metodológico, la instrumentación de procesos de planeación y la consecuente institucionalización de Planes de Manejo" (Valadez Moreno \& Huitrón Santoyo, p. 52). En ese sentido, algunos factores importantes de esta nueva propuesta fueron un enfoque de largo plazo (conservación, investigación, proceso, interpretación, uso público y administración), objetividad, enfoque territorial y enfoque sistémico. En ese marco, un
Figura 4. Los centros históricos de México inscritos en la Lista del Patrimonio Mundial. En "La gestión urbana de los centros históricos" (p. 191), por P. F. Gómez, 2013. Estudios sobre conservación, restauración y museología, l., México, 2013. 
plan de manejo "se entiende como un instrumento de política institucional que asegura la dirección de los procesos de conservación, investigación, protección y difusión" (Valadez Moreno \& Huitrón Santoyo, p. 54), que es elaborado y ejecutado por el INAH. Sin embargo, a pesar de estas iniciativas y la implementación de herramientas para la gestión de los centros históricos, los resultados no han sido positivos en todos los casos, pues existen muchos factores que aún generan dificultades en el proceso de planeación y gestión. En ese sentido, por ejemplo,

...la autonomía municipal otorgada desde la Constitución Política de los Estados Unidos Mexicanos en materia de planeación urbana, y los preceptos de la Ley General de Asentamientos Humanos, generan diferentes criterios, procedimientos y políticas locales en la gestión urbana, que incluye los centros históricos. (Gómez Porter, 2013, p. 192)

Respecto al financiamiento para la gestión de centros históricos, existen los recursos fiscales, pero también otras alternativas que permitan obtener recursos a través de impuestos locales o por medio de impuestos directos a los "beneficiarios". También se cuenta con instrumentos de fomento para el financiamiento, como los incentivos fiscales, las facilidades administrativas (para proyectos de desarrollo urbano, por ejemplo), el sistema de transferencia de derechos y los subsidios. En esta línea, las entidades e instituciones que participan en la inversión son la Secretaria de Turismo (SECTUR), la SEDESOL y el FONCA, así como el programa Hábitat-Vertiente Centros Históricos, y los gobiernos locales y estatales (Abrin Frutos, 2008).

En el caso específico del Programa Hábitat de México, en 2003 el Gobierno federal de México lo institucionalizó a través de SEDESOL, con la finalidad de "articular los objetivos de la política social con los de la política de desarrollo urbano y ordenamiento territorial del Gobierno Federal, para contribuir a reducir la pobreza urbana y mejorar la calidad de vida en zonas urbanas marginadas" (SEDESOL, 2011, p. 2). Este programa presenta dos vertientes. En primer lugar, la Vertiente General, que tiene como referente el Plan de Acción de la ONU-Hábitat, donde se indica que

...la rehabilitación y conservación de espacios culturalmente sensibles a la adaptación de zonas urbanas patrimonio de la humanidad coinciden con el uso sustentable de los recursos naturales y humanos, porque todas las personas deben poder beneficiarse del acceso a la cultura. (Ortiz Espinoza, Cabrera Iriberri \& Hernández, 2013, p. 170)

En segundo lugar, está la Vertiente Centros Históricos, a la cual Hábitat destinó el 1.9\% de sus recursos, monto que, sin embargo, es insuficiente, motivo por el cual SEDESOL buscó otorgar más recursos de forma indirecta a través del apoyo técnico-administrativo, con la participación del INBA y el INAH. Asimismo, el programa implementó subsidios a través de los mismos municipios, cubiertos en $70 \%$ por el gobierno federal y en $30 \%$ por el gobierno municipal, los cuales son asignados anualmente a cada uno de los 10 centros históricos declarados Patrimonio de la Humanidad en México.

Si bien a partir de la década del 50 el patrimonio cultural en conjunto se vuelve paulatinamente objeto de interés en el plano económico a través del turismo, es partir de la creación del SECTUR (1989) que el patrimonio arquitectónico pasa a un primer plano, lo cual da lugar al desarrollo de los Fondos Mixtos Ciudades Coloniales, que son

...mecanismos de participación conjunta en las que interviene el gobierno federal, el gobierno estatal, el gobierno municipal, así como los prestadores de servicios turísticos organizados a través de la misma Secretaria para impulsar el desarrollo de la actividad turística por medio de la publicidad, promoción y comercialización tanto en el mercado nacional como internacional. (Sánchez López, 2000, párr. 37)

Asimismo, a este programa se suma la Asociación Nacional de Ciudades Mexicanas del Patrimonio Mundial (1996), organismo que se encarga de "gestionar apoyos financie- 


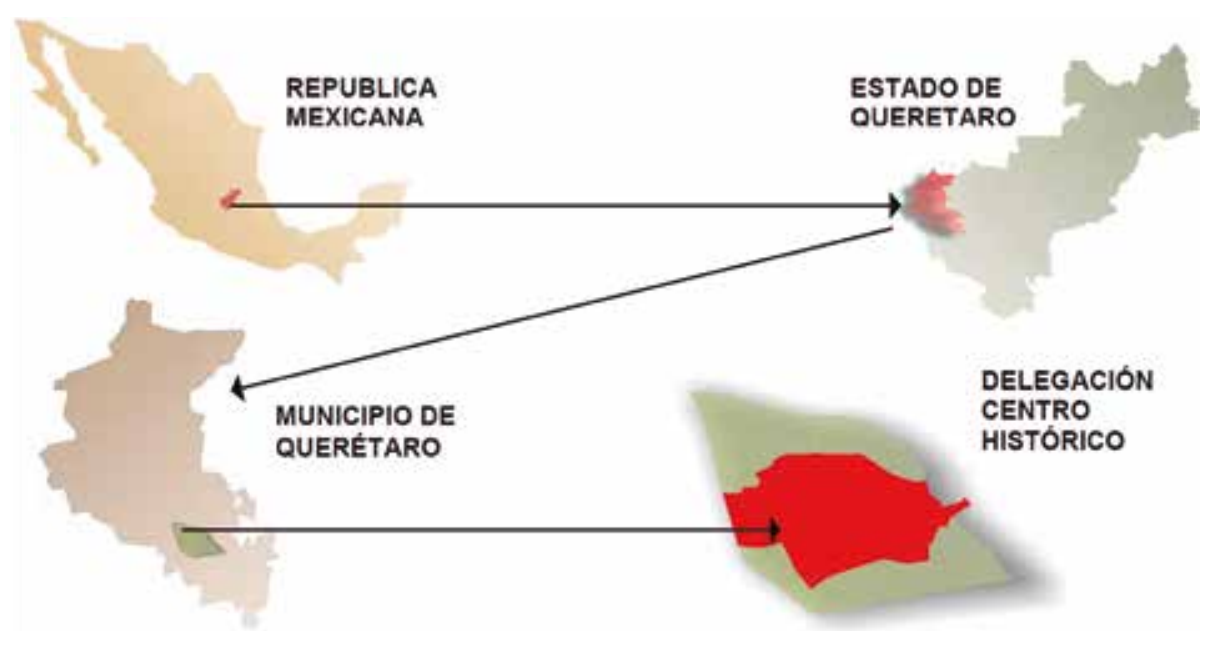

ros públicos y privados, nacionales e internacionales, mismos que destinarán, para que sus ciudades miembro, preserven, mejoren, difundan y mantengan sus centros históricos, en beneficio directo de los habitantes del Municipio, así como a los visitantes en general" (Tapia Ibarra, 2006, pp. 75-76).

\section{Querétaro}

Cada estado mexicano está divido en municipios (gobernados por el ayuntamiento), y estos a su vez en delegaciones. Santiago de Querétaro corresponde a una de las siete delegaciones ${ }^{3}$ que conforman el municipio de Querétaro (Figura 5), el cual a su vez es uno de los 18 municipios del estado de Querétaro (denominado hasta 2010 Querétaro de Arteaga). Al respecto, es posible indicar que dicha división territorial tiene efectos positivos, debido a que

...busca que las autoridades competentes tengan un análisis urbano más detallado sobre la ciudad (a través de la realización de cartas urbanas, planes municipales, reglamentos, etc.) y que el crecimiento de la metrópoli se realice de una manera más ordenada satisfaciendo los objetivos gubernamentales para el desarrollo de la ciudad. (Reyes Nieto, Simoes da Silva, Murthino, Rigueiro, \& Gonzales, 2015, p. 1830)

Esta delegación cobra mayor importancia al considerar que fue testigo de varios eventos que marcaron la historia de la formación de la República de México: en 1810 tuvo lugar la llamada "Conspiración de Querétaro", que dio inicio a las guerras de Independencia; en 1867 las fuerzas republicanas derrotaron y dieron muerte al emperador del Segundo Imperio mexicano Maximiliano Habsburgo, lo que significó el fin de la monarquía implantada en este país; en 1917 fue sede del Congreso Constituyente que promulgó la primera Constitución Política de los Estados Unidos de México; en 1929 se fundó allí el Partido Nacional Revolucionario (PAN), que luego se convirtió en el Partido Revolucionario Institucional (PRI), el partido mexicano de mayor protagonismo político; y en 1996 su Centro Histórico fue declarado Patrimonio de la Humanidad.

En cuanto a la población, el censo de 2010 registró en la ciudad de Santiago de Querétaro 801,940 habitantes. Asimismo, cabe indicar que la mayoría de la población es joven y se encuentra en edad trabajadora: 46.23\% es menor de 25 años (Reyes Nieto, Simoes da Silva, Murthino, Rigueiro, \& Gonzales, 2015, p. 1830).
3. Forman parte también las Delegaciones de Epigmenio Gonzáles Flores, Felipe Carrillo Puerto, Félix Osores Sotomayor, Josefa Vergara y Hernández, Santa Rosa Jáuregui y Villa Cayetano Rubio.
Figura 5. Ubicación del Municipio de Santiago de Querétaro. En Plan de Manejo de la Zona de Monumentos Históricos de Santiago de Querétaro, por IMPLAN Querétaro, 2011. 
devenir Vol. 5, N9, ENERO - JUNIO 2018, PP. 117-136 - ESTUDIOS I ISSN 2312-7562 I E-ISSN 2616-4949

UNIVERSIDAD NACIONAL DE INGENIERÍA, LIMA

\section{Parques industriales de Querétaro}

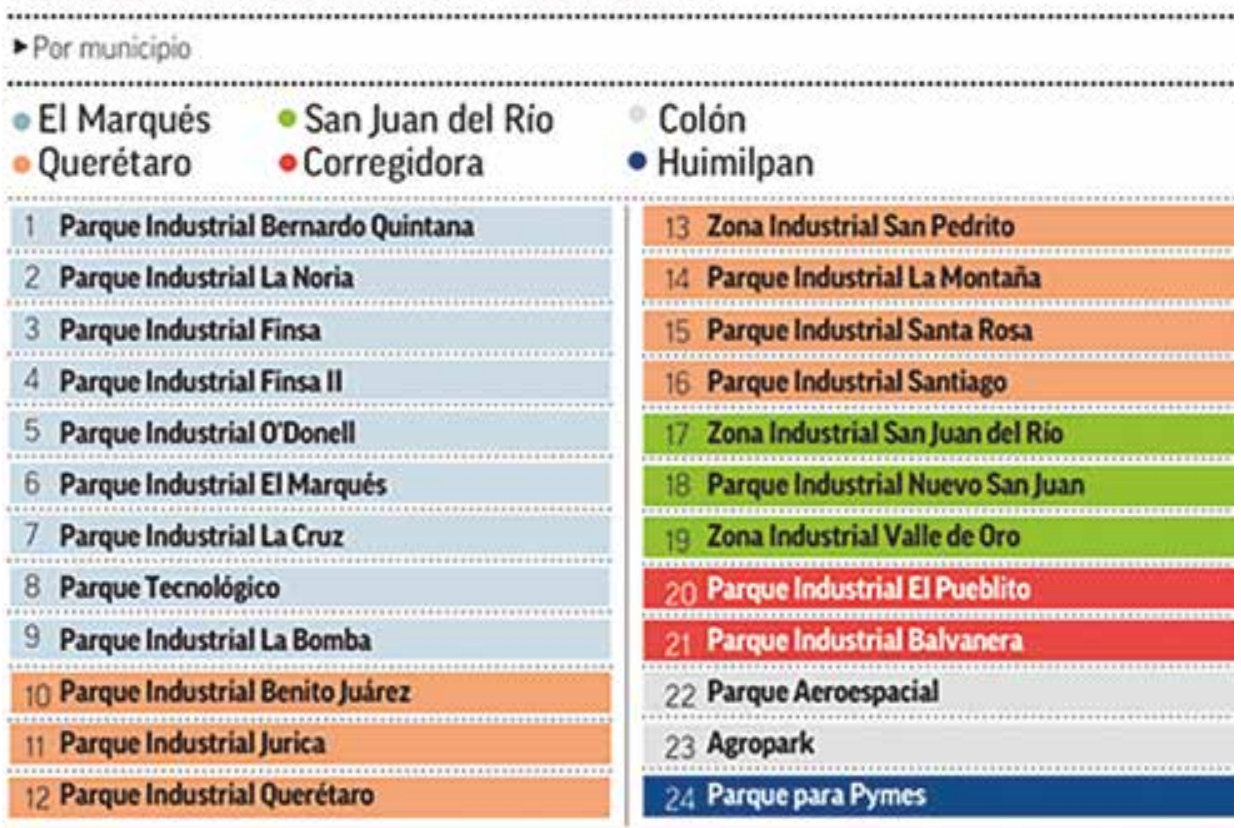

Figura 6. Parques industriales del estado de Querétaro. Recuperado de http://www.elfinanciero.com.mx/economia/queretaro-apuesta-por-la-desconcentracion-industrial.html

\section{Economía}

La economía ha variado significativamente, lo cual ha convertido a Santiago de Querétaro en una de las ciudades más ricas de México. Si bien hasta la primera mitad del siglo XX su economía se basaba aún en la actividad agropecuaria (de carácter primario), ya en la segunda mitad se dio inicio al desarrollo del sector industria (actividad secundaria), en el que destacan la producción automotriz, aeronáutica, alimentaria y de tecnologías de la información.

Es necesario anotar que las políticas federales para sustituir las importaciones promovieron el desarrollo de la industria nacional, y se estableció en la década del 60 un proceso de industrialización sostenido en el estado de Querétaro, debido a que ocupa una ubicación estratégica dentro del territorio mexicano (está muy próximo al estado de México), lo cual lo convirtió en el referente de la región del Bajío mexicano. A esto se sumó la presencia de centros de investigación y desarrollo, además de la construcción en 1985 de la autopista México-Querétaro, conocida como la "Carretera 57", que generó un "eje carretero" junto con la carretera federal 45, en relación al cual fueron ubicados los parques y zonas industriales.

Hacia la década del 70, el proceso de industrialización incrementó, producto de las políticas de descentralización de las industrias de la zona metropolitana de la ciudad de México. Luego de esto, en la década del 80 fueron implementadas las políticas de libre comercio, frente a la sustitución de importaciones, lo cual dio lugar a la apertura a los capitales extranjeros, que a su vez generó un incremento en la cantidad de parques industriales de Querétaro (Figura 6).

Finalmente, desde la década del 90 hasta la actualidad, Querétaro reporta una baja en la participación del sector secundario, lo cual ha significado un decrecimiento de la importancia del sector industrial. Sin embargo, "la industria aún constituye un elemento dinamizador de la economía pues, en términos absolutos, aumentó tanto su participación como la generación de servicios -transporte, almacenamiento, actividades financieras y de seguro-" (Icazurriaga Montes \& Osorio Franco, 2007, p. 23). A partir 

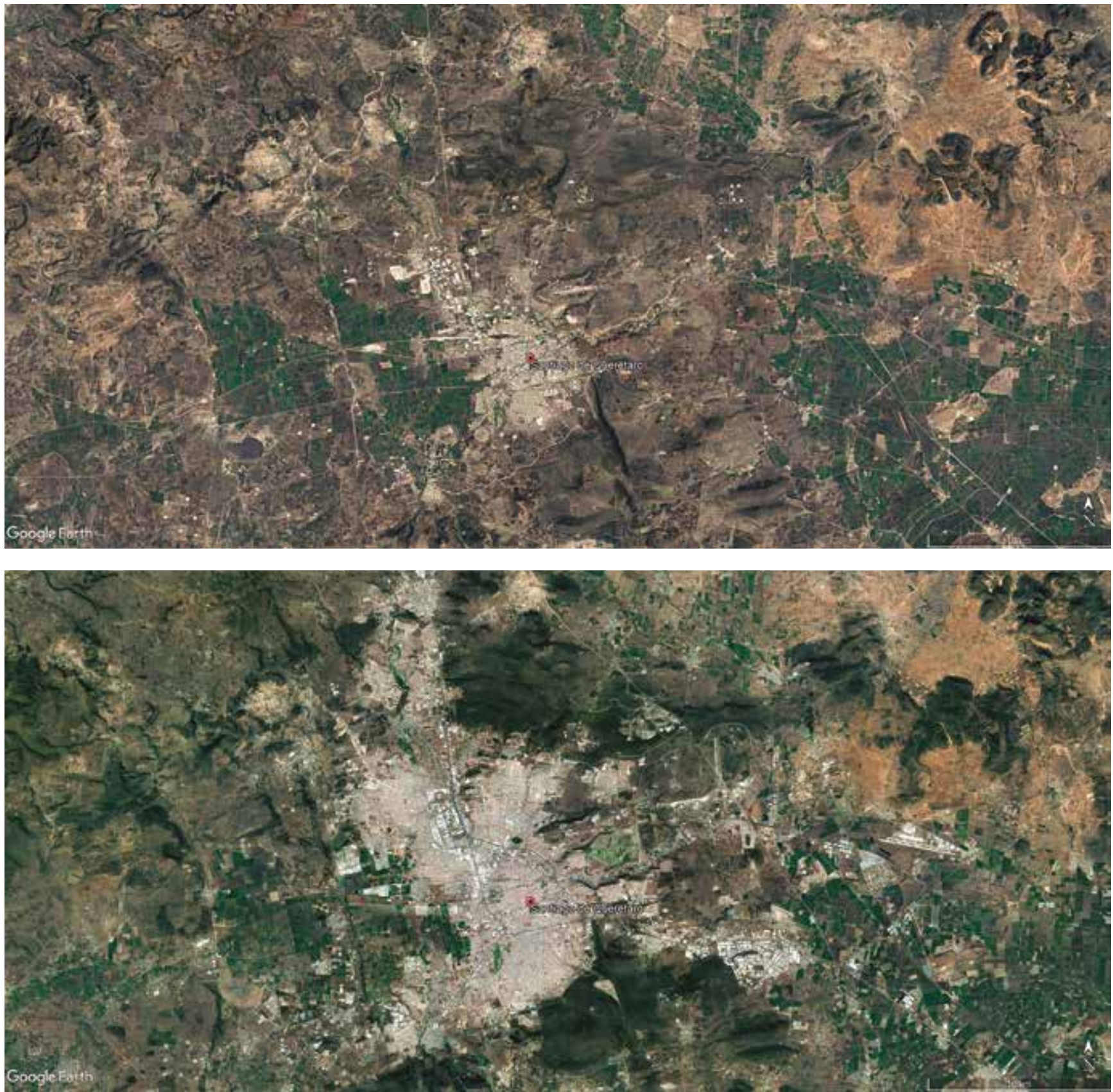

de esto, en el 2010 la ciudad Santiago de Querétaro tuvo una actividad industrial que generó el $67 \%$ del PBI del Estado.

\section{Planificación urbana}

A partir de lo anterior, es posible considerar que el proceso de industrialización ( $y$, últimamente, el turismo) es el factor principal que ha causado crecimiento urbano en el municipio de Querétaro. Esta expansión de la zona metropolitana ha absorbido cada vez más área antes agrícola, y se ha configurado una nueva distribución urbana. Así, en Querétaro tuvo lugar un proceso de conurbación, entendido como la "articulación socioespacial derivada de la aparición de nuevas actividades urbanas en los pueblos
Figura 7. Santiago de Querétaro en 1984, antes de la mayor expansión urbana. Google Earth, 2017.

Figura 8. Santiago de Querétaro en 2017, luego de la expansión urbana. Google Earth, 2017. 
devenir Vol. 5, N9, ENERO - JUNIO 2018, PP. 117-136 - ESTUDIOS I ISSN 2312-7562 I E-ISSN 2616-4949

UNIVERSIDAD NACIONAL DE INGENIERÍA, LIMA

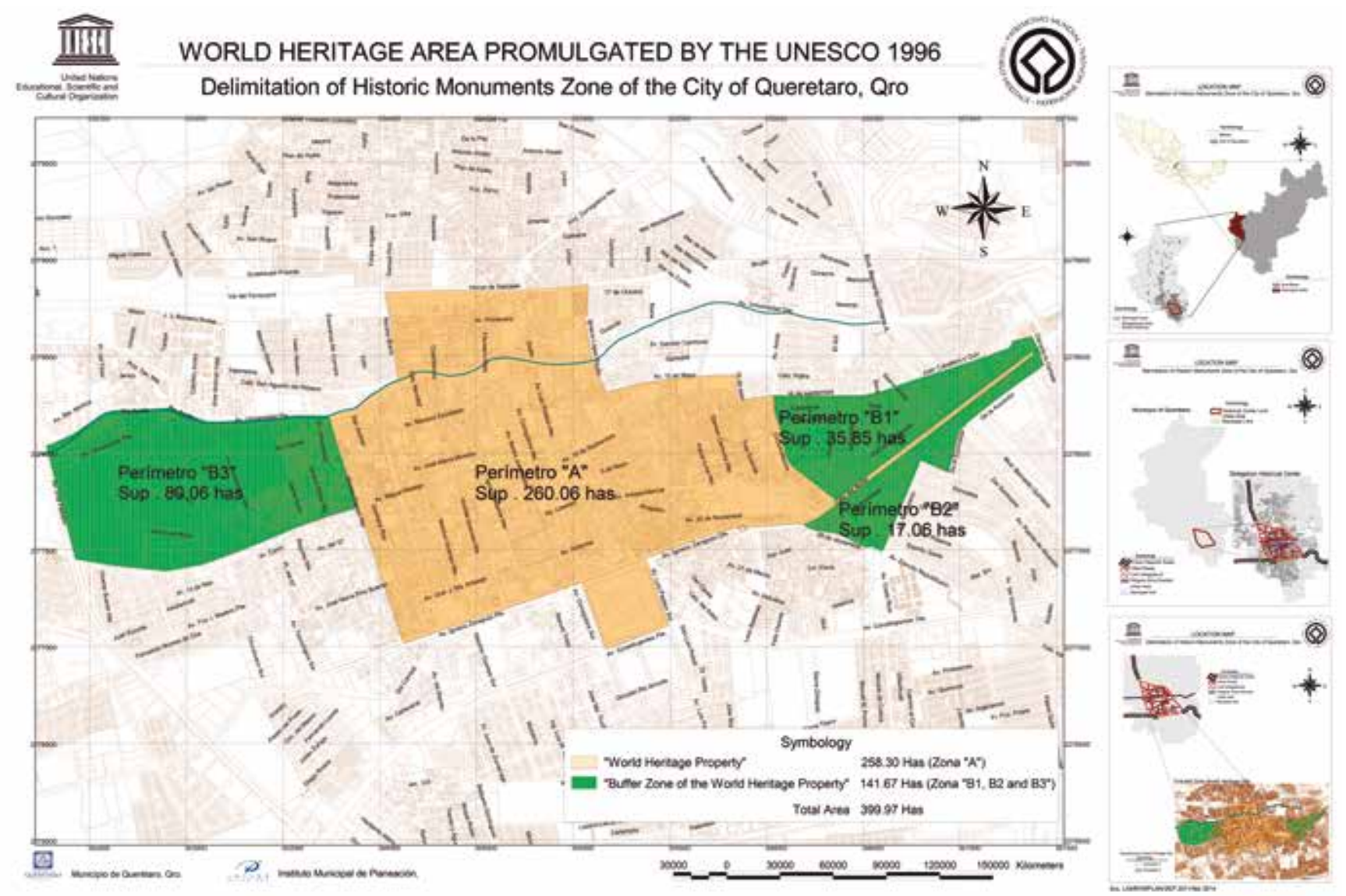

Figura 9. Plano de la Zona de Monumentos Históricos de Santiago de Querétaro. Recuperado de http.//implanqueretaro.gob.mx//im/st/4/1/1/ DeclaratoriaFederal.pdf conurbados y de la destrucción de la economía precedente, casi siempre agrícola" (Icazurriaga Montes \& Osorio Franco, 2007, p. 23), por lo cual en 1992 el Consejo Nacional de Población (CONAPO) estableció la Zona Conurbada de Querétaro, conformada por los municipios de Querétaro, Corregidora, El Marqués y Huimilpan.

Esto indica que si bien la ciudad de Querétaro no presenta mayor explosión demográfica, el crecimiento se ha dirigido hacia la zona periférica, lo cual ha generado variaciones en el uso y la ocupación, y ha modificado las características rurales que presentaban inicialmente dicha zona (Figuras 7 y 8). Para definir esta situación, Icazurriaga y Osorio emplean los conceptos de ciudad interior y ciudad exterior: la primera es "aquella área de la ciudad en la cual se concentran los servicios y que tiene la mayor densidad habitacional, pero también cuenta con zonas de viviendas degradadas", mientras que la segunda es "donde los asentamientos son dispersos y van creciendo en torno a los ejes viales-carreteros" (2007, p. 25).

El incremento de la población en las zonas de expansión urbana ha tenido como resultado un incremento en la construcción de viviendas, que ha generado varios proyectos para la habilitación de fraccionamientos cerrados, los cuales fueron establecidos en propiedades privadas y a cargo de empresas inmobiliarias; así también fueron habilitadas las colonias y condominios, que fueron establecidos principalmente en territorios invadidos. Sin embargo, el incremento de estos proyectos constructivos dio lugar a que la oferta de viviendas sea mayor que la demanda, lo que ha generado un problema frente al cual el gobierno planteó una estrategia por medio de programas de crédito, a través del Instituto del Fondo Nacional de Vivienda para los Trabajadores, 


\section{Población en el área de actuación del PMCZMHSQ}

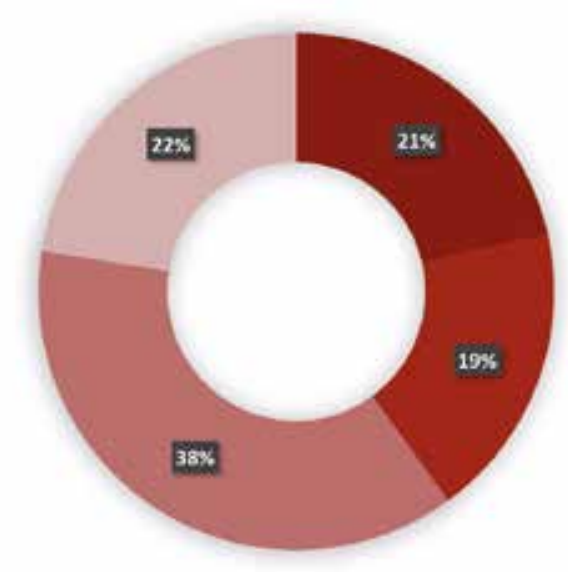

- Perimetro " $\mathrm{A}$ ". Zona de monumentos históricos

- Perimetro "B"

$=$ Zona de barrios tradicionales

$=$ Zona de amortiguamiento para los trabajadores dependientes, y por medio de la Comisión Nacional de Vivienda y la Banca privada, para los trabajadores independientes.

Asimismo, si bien inicialmente se establecieron en la ciudad interior las primeras plazas comerciales ${ }^{4}$, la expansión urbana dio lugar a que en la década del 90 estas se incrementaran, pero cerca de fraccionamientos, y de las zonas residenciales de niveles medio y alto. A su vez, esto generó que el centro histórico de Santiago de Querétaro atravesara
Figura 10. Población reportada para 2010 en el área de actuación del PMCZMHSQ. Elaboración propia sobre la base de Tabla II.3 del Plan de Manejo de la Zona de Monumentos Históricos de Santiago de Querétaro, por IMPLAN Querétaro, 2011.

....otra modificación en su imagen: de ser un centro de servicios y comercios para la población residente (consultorios, laboratorios, despachos de abogados, etcétera), se vuelva uno en mayor grado para el turismo (hoteles, galerías, restaurantes, cafeterías, bares, estacionamientos, tiendas de artesanías), disminuyendo los servicios y comercios que antes estaban dirigidos sobre todo a las oficinas (papelerías, farmacias, loncherías, fondas). Esto obedece en una medida a que 'sacaron' de esta zona a muchas oficinas administrativas municipales y a los juzgados, que fueron reubicados en lo que hoy día se considera la periferia del área urbana (Icazurriaga Montes \& Osorio Franco, 2007, p. 26)

\section{Santiago de Querétaro. Gestión de la zona de monumentos históricos}

La traza urbana de Santiago de Querétaro quedó definida ya en el siglo XVI, luego de que en este territorio se desarrollaran sociedades indígenas que estuvieron en constante proceso de interacción y dejaron una impronta de diversidad cultural, que se acentuó con la llegada de los españoles, que implicó mestizaje cultural. Así, "la cultura local, producto de esa mezcla heterogénea se manifiesta en el espacio urbano, en la traza, en la arquitectura civil y religiosa, en sus costumbres y tradiciones, en las propias instituciones, así como en muy diversas expresiones" (Instituto Municipal de Planeación Querétaro [IMPLAN Querétaro], 2010, p. 4).

En 1981 el Gobierno federal estableció la Zona de Monumentos Históricos de la Ciudad de Querétaro (ZMHCQ), una zona de conservación que comprendía un área de $4 \mathrm{~km}^{2}$ y que abarcaba 203 manzanas, donde se ubicaron aproximadamente 1,400 edificios con valor histórico que habían sido construidos entre los siglos XVI y XIX. El área donde se ubican la mayor cantidad de edificios con valor histórico se denomina perímetro $A$, y el área donde se encuentran el acueducto y el Cerro de las Campanas, perímetro B. En 1995 el área que

4. Se debe entender a las plazas comerciales como espacios de comercio, donde destaca una gran firma y a su alrededor se ubican otros establecimientos menores. 
comprende el Centro Histórico y los barrios tradicionales de la Ciudad de Querétaro fue declarada Zona de Conservación, y se elaboró el reglamento para la Emisión de Declaratorias de Monumentos y Zonas de Conservación en el Municipio de Querétaro.

Asimismo, en 1996, con la participación del INAH, la ZMHQ fue inscrita en la lista de Patrimonio Mundial de la UNESCO (Figura 9), considerándose dos de los seis criterios culturales: los criterios ii y iv. Finalmente, esta declaratoria dio lugar a la elaboración de un instrumento de gestión que corresponde al Plan de Manejo y Conservación de la Zona de Monumentos Históricos de Querétaro (PMCZMHQ), presentado en 2011 por parte del IMPLAN Querétaro, donde se indica que

....la estructura urbana del Centro Histórico de la ciudad de Santiago de Querétaro está compuesta, desde sus orígenes, por un esquema centro periferia, el centro, ubicado en la ZMHQ, al sur del río Querétaro, con presencia de vivienda formal de carácter regular y en su mayoría muy antiguas. Incrustándose entre las áreas de vivienda se encuentran zonas de servicios cuyas lógicas de localización son más históricas y circunstanciales que genéricas. Hacia las periferias se presentan la vivienda de origen menos formal, de carácter contextual y vinculado a la conformación de los denominados barrios tradicionales, en particular, los barrios de la "Otra Banda", segregados del núcleo formativo de la ciudad por el río Querétaro y en la ribera norte de éste (IMPLAN Querétaro, 2011, II-25-II-26).

Es ese documento el que aquí se empleará como referencia para describir algunos datos puntuales que fueron recogidos dentro del área de actuación del PMCZMHQ, el mismo que al final permitirá realizar la evaluación de los aspectos positivos y negativos de su desarrollo, y la búsqueda de su aplicación.

- La población identificada en el área de actuación al momento de elaborar el plan de manejo ascendía a 86,280 habitantes, lo que comprendía el $14.83 \%$ de la población del Municipio de Querétaro (Figura 10).

- Las actividades secundarias comprendían el 29.22\%, mientras que las terciarias (alimentos, abarrotería, comercio de ropa y servicios de turismo) abarcaban el $66.81 \%$ de las actividades económicas registradas en el área de actuación, donde la población ocupada constituía el 98\% del PEA.

- También se registraron niveles bajos de marginación, es decir: viviendas precarias, falta de servicios de salud y educación, ingresos monetarios insuficientes o desigualdad de género.

- A partir del análisis de los procesos de desvalorización, declinación, deterioro y degradación, se resume un diagnóstico que recoge algunos aspectos que afectan al patrimonio presente en la ZMHQ: la zona aledaña al río Querétaro sufre una desvalorización por problemas de accesibilidad que causa el mismo río, así como la presencia de las vías de ferrocarril, lo cual está generando procesos de deterioro físico en el patrimonio construido. También se identificó que la desvalorización y el deterioro del patrimonio es producto de la falta de inversión, tanto pública como privada. Esto puede ser consecuencia del mayor interés por la zona de la periferia, en detrimento de la ciudad interior. Una tercera causa de la desvalorización es la falta de políticas, y proyectos de reaprovechamiento del río y sus márgenes. Finalmente, el río Querétaro no forma parte del imaginario actual de la población urbana, "al menos no como un valor para cuidar y disfrutar, para los grupos de mayor edad sí representa un hito, más anecdótico que real" (IMPLAN Querétaro, 2011, II-27).

- El cambio de uso de suelo (terciarización) es claro, pero de tendencia moderada hacia la parte central de la ZMHQ, y disminuye hacia las periferias, principalmente hacia el Norte.

- La sociedad civil muestra interés por la conservación y puesta en valor del centro histórico a través de las acciones realizadas por asociaciones culturales y sociales, 


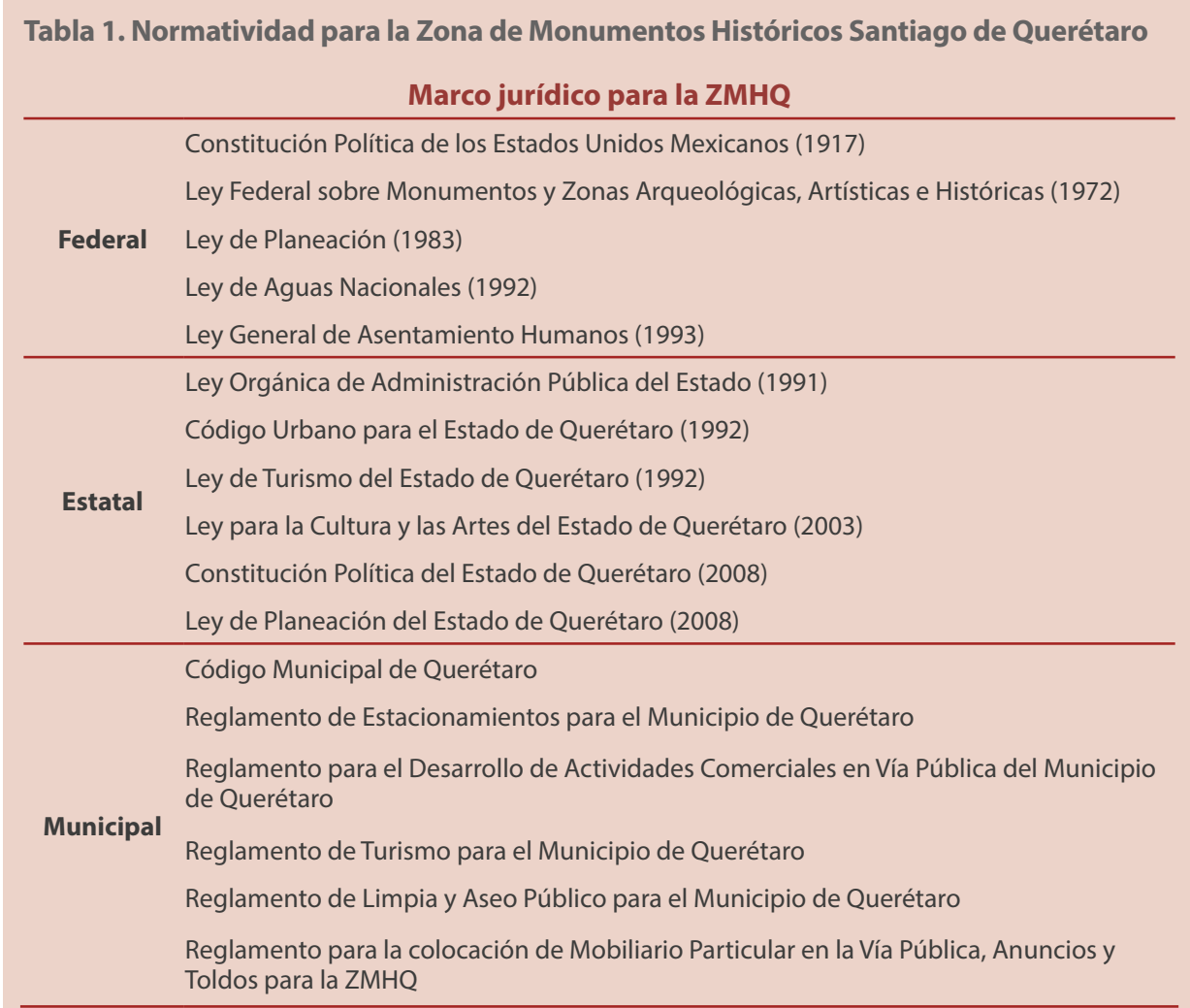

Elaboración propia sobre la base de capítulo Marco Legal I-10: I-27 del Plan de Manejo de la Zona de Monumentos Históricos de Santiago de Querétaro, por IMPLAN Querétaro, 2011.

instituciones empresariales y profesionales, además de universidades; sin embargo, esta población se encuentra vinculada principalmente con las actividades religiosas y las festividades tradicionales, por lo cual en este documento se anota que

....fuera de esta dinámica se identificó que no hay mucha unidad en cuestiones de interés colectivo con mejorar su entorno. Es necesario acotar que dentro de los resultados sobre la identificación de personas con liderazgo, en promedio siete de cada diez personas no reconoció a persona alguna con una representación importante. (IMPLAN Querétaro 2011, II-35)

Por ello, se considera que la participación de la población es institucionalizada. Las principales instituciones vinculadas a la gestión de la ZMHQ son a) el Sistema de Consejos Municipales de Participación Social, b) ICOMOS Querétaro, c) el Patronato del Centro Histórico de Querétaro y d) las organizaciones gremiales de profesionales. Asimismo, a nivel gubernamental se encuentran involucrados en la conservación y rehabilitación el INAH Querétaro y el Municipio de Querétaro (Secretaría de Servicios Públicos Municipales, Secretaría de Desarrollo Sustentable, Secretaría de Obras Públicas Municipales, Oficina Delegación Centro Histórico e IMPLAN).

- La normatividad para la gestión de la ZMHQ abarca los tres niveles gubernamentales: federal, estatal y municipal (Tabla 1).

- En el área de actuación se ha registrado que casi el 100\% de la población cuenta con sistema de agua potable y de alcantarillado; sin embargo, estos son muy antiguos, e inclusive tienen filtraciones que generan daños paulatinos a los edificios 
devenir Vol. 5, N9, ENERO - JUNIO 2018, PP. 117-136 - EstudIOS I ISSN 2312-7562 | E-ISSN 2616-4949
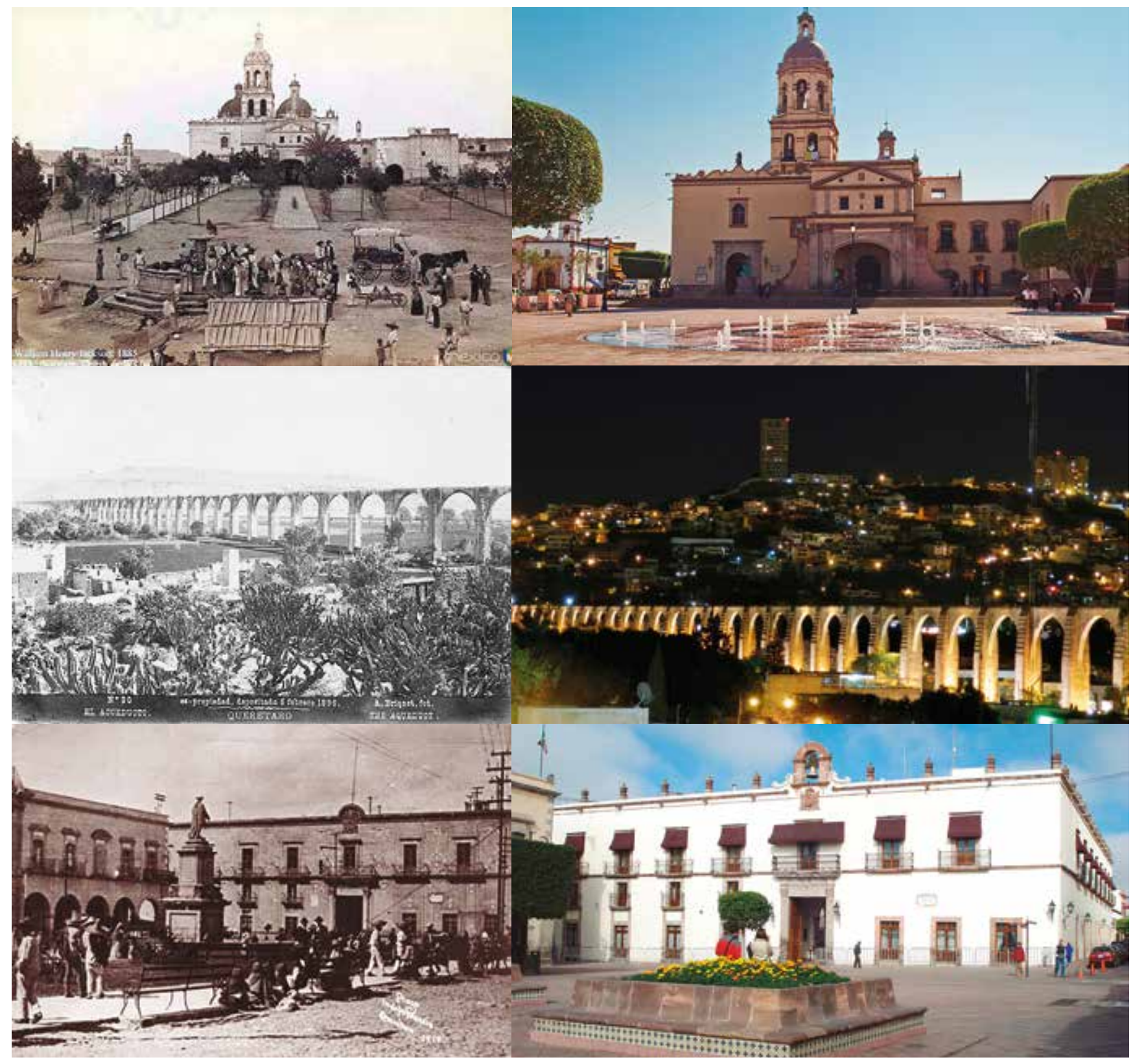

Figura 11. Templo y exconvento de la Santa Cruz, construido en el s. XVII, 1885. Recuperado de https://www.mexicoenfotos.com/antiguas/queretaro/queretaro/convento-de-la-santa-cruz-1885-MX12182438929484

Figura 12. Templo y exconvento de la Santa Cruz, 2015. Recuperado de http://www.de-paseo.com/queretaro/item/la-santa-cruz/

Figura 13. Acueducto de Querétaro, construido en el s. XVIII, 1896. Recuperado de http://www.aquiqueretaro.com/images/Queretaro/AcueductoQro1896.jpg

Figura 14. Panorámica del Acueducto de Querétaro en la actualidad, declarado Patrimonio Mundial. Recuperado de https://aliamex.com/noticias/ ciudad-de-queretaro-tasa-alta-tic/

Figura 15. Plaza de la Independencia y Casa de la Corregidora, 1919. Recuperado de http://www.ciudadypoder.mx/el-antes-y-ahora-de-estos-lugares-de-queretaro/

Figura 16. Casa de la Corregidora en la actualidad, edificio construido en el s. XVIII, utilizado como Casa Real y cárcel. Desde 1981 es Palacio de Gobierno, sede del Poder Ejecutivo del Estado de Querétaro, México. Recuperado de http://espacioqueretaro.com/casa-de-la-corregidora/ 


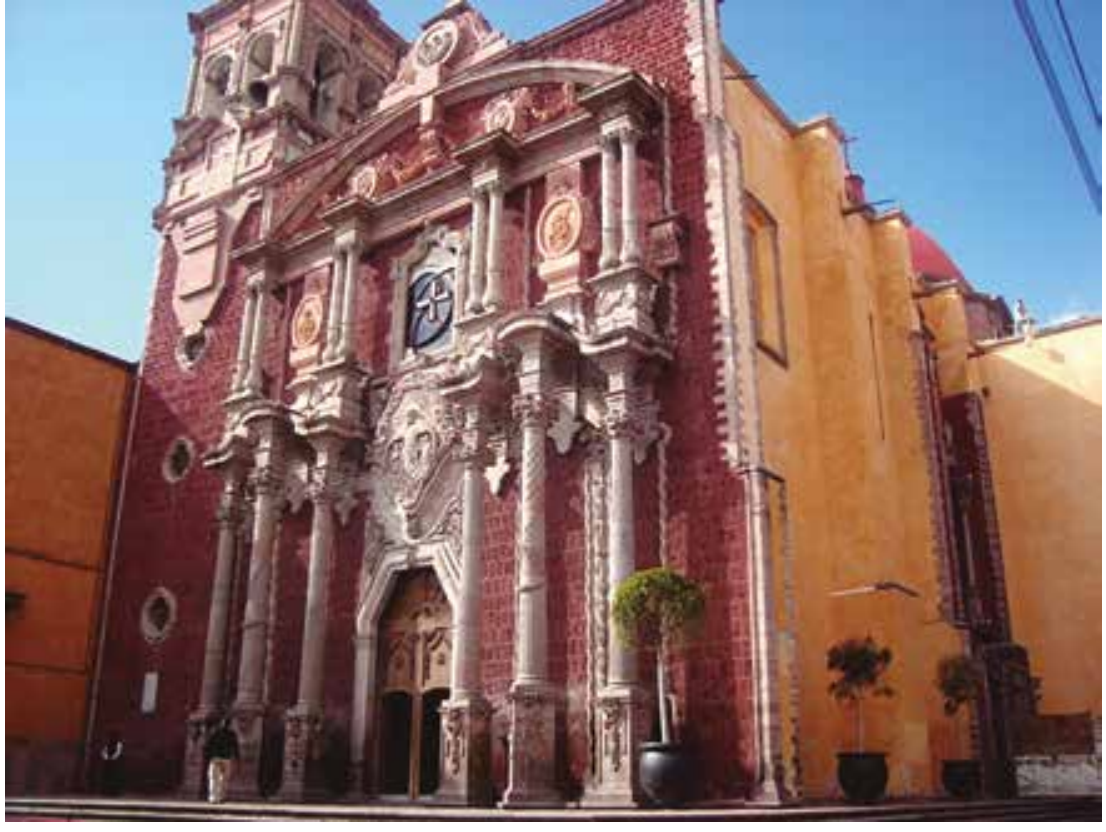

que conforman la ZMHQ. Asimismo, el sistema de alumbrado público está completo, pero solo una parte mínima ha sido cambiada a cableado subterráneo.

- La seguridad pública es un aspecto a considerar: en algunas áreas (barrios tradicionales principalmente) se registran continuos asaltos y robos.

- Finalmente, en este documento (PMCZMHQ) fue planteada la creación de una unidad de gestión, que se encargaría de la ejecución de la gestión de la ZMHQ. Así, esta estaría comprendida por a) un órgano de gobierno, b) un órgano consultivo y 3) una estructura de operación. Asimismo, fueron considerados como mecanismos de control a) un sistema de información urbana y b) la formulación de indicadores de seguimiento y evaluación, sobre la base de un Sistema de Información Geográfica, que permita recuperar una base de datos del patrimonio presente en la ZMHQ, y así realizar una evaluación y monitoreo adecuado de la misma.

Por lo expuesto, cabe tener en cuenta que el PMCZMHQ fue planteado como un instrumento participativo y concertado, para el cual se buscaba una personalidad jurídica y un patrimonio propio, pero terminó siendo una herramienta que quedó en el plano de la propuesta, ya que entre el periodo 2013-2015 no continuó en operación, tal como quedó expresado en el libro Querétaro, Zona de Monumentos Históricos. Patrimonio Cultural de la Humanidad, presentado por el Municipio de Querétaro en el año 2016, donde se plantea la creación de un nuevo comité para la gestión de la ZMHQ. Sin embargo, esta propuesta no ha tenido mayor eco; por lo tanto, a pesar de haber transcurrido más de 20 años de su declaración como Patrimonio Mundial, en la ZMHQ

...es notorio el incremento de la actividad en el centro de la ciudad, en el cambio de uso de suelo de habitacional a comercio y servicios, la existencia de más de 80 inmuebles abandonados y estado ruinoso identificados por el INAH, IMPLAN, y la Dirección de Sitios y Monumentos de Estado. Las condiciones de inseguridad al ser una de las zonas con mayor índice de robos y asaltos. El incremento del mercado inmobiliario con la sobreoferta de inmuebles en venta y la especulación del patrimonio cultural edificado, pero sobretodo el desplazamiento de los residentes originarios ante una oferta económica atractiva que no pueden desechar. (Jiménez Guillén, 2016, párr. 14)
Figura 17. Catedral de Querétaro. Recuperado de https://www.turimexico.com/estados-de-la-republica-mexicana/queretaro-mexico/monumentos-historicos-de-queretaro/ catedral-queretaro/ 


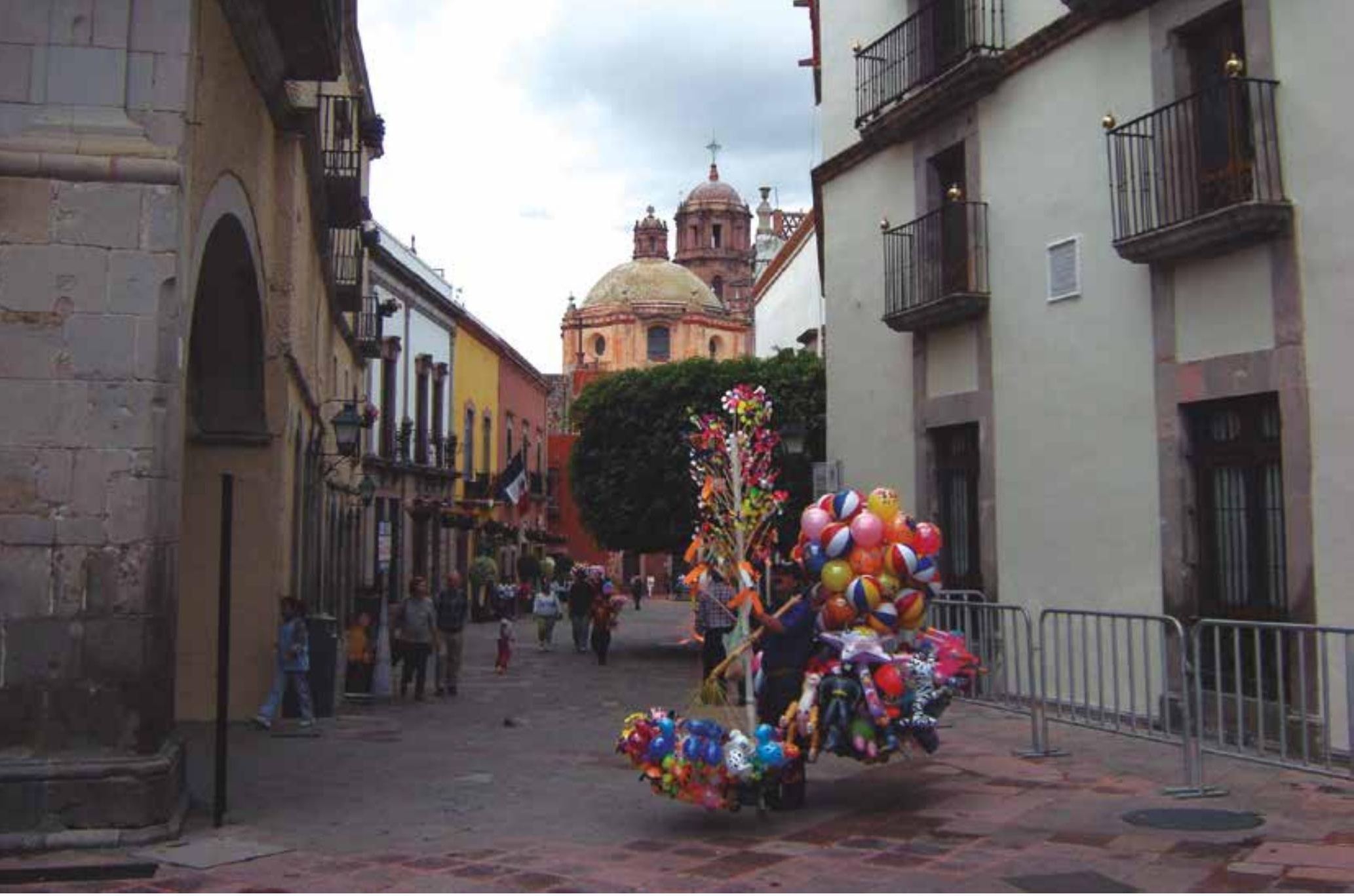

Figura 18. Calles del Centro Histórico de Santiago de Querétaro. Recuperado de https://es.wikipedia.org/wiki/ Archivo:Vista_da_Plaza_de_la_Independencia_(4012714374).jpg

\section{Conclusiones}

Tomando como referencia el texto analizado, así como los distintos documentos de gestión y trabajos de investigación relacionados a la $\mathrm{ZMHQ}$, se distinguen una serie de problemas que no necesariamente han sido resueltos a lo largo de las dos últimas décadas y que es necesario abordar para alcanzar soluciones concretas e integrales. En relación a ese objetivo, cabe mencionar algunas conclusiones que recogen los problemas principales de la gestión de la ZMHQ.

La transformación urbana que ha tenido lugar en Querétaro ha generado problemas de distinta índole (Figuras 11, 12, 13, 14, 15 y 16). Entre estos, se debe considerar el proceso de gentrificación que se reporta en la $Z M H Q$, que genera el cambio de uso del suelo, que se torna comercial, ante el previo uso habitacional. Es necesaria la implementación de proyectos que tengan como objetivo detener este proceso, que generen condiciones adecuadas para que los actuales dueños permanezcan, como incentivos o financiamiento (público y/o privado) para la recuperación y conservación de los bienes inmuebles, y así mantener un uso acorde a la valorización del patrimonio edificado.

Por otro lado, el proceso de industrialización, que comprendió la construcción de carreteras estatales como la carretera 57 (entre otras), se traduce en una mayor carga de transporte hacia la ZMHQ. Asimismo, este fenómeno, sumado al incremento del turismo, que ha dado lugar a la presencia de una mayor cantidad de visitantes, genera un tráfico que satura las vías de comunicación hacia el interior. Sobre lo anterior, cabe agregar que el incremento del tránsito está directamente relacionado con la presencia de vehículos de uso particular, y aquellos asociados al comercio y servicios, que requieren espacios exclusivos para su estacionamiento, por lo cual el municipio de Querétaro ha implementado algunas estrategias de solución como el Reglamento de Estacionamientos para el Municipio de Querétaro, que aún no obtiene resultados posi- 

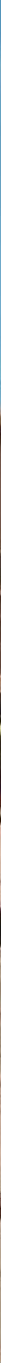

tivos. Ante este problema, podría optarse por implementar programas de transporte público, así como habilitar vías peatonales (Figura 17).

La protección de la ZMHQ es de interés colectivo; sin embargo, los instrumentos de gestión no necesariamente han contemplado la participación de la comunidad involucrada ni han reconocido a los actores involucrados en el proceso de planeamiento y ejecución (Ver Figura 18). Asimismo, a pesar de la participación de una serie de instituciones, las iniciativas no necesariamente se encuentran coordinadas en función a los procesos de conservación; en ese sentido, se han elaborado una serie de herramientas de gestión, como el PMCZMHQ, y reglamentos municipales para la protección de la $\mathrm{ZMHQ}$, los cuales deberían estar involucrados en un sistema de gestión que comprenda además financiamiento, y cooperación internacional para la efectiva ejecución de los distintos proyectos y programas que se han elaborado, y serán elaborados. Asimismo, es necesario establecer los indicadores de conservación de la $Z M H Q$, que permitirán llevar a cabo el monitoreo y evaluación de su protección, conservación y mejora (Figura 19).

Finalmente, si bien el Plan de Manejo y Conservación para la ZMHQ contiene un diagnóstico que abarca muchos aspectos importantes para la propuesta de soluciones adecuadas a corto, mediano y largo plazo, resulta ser una herramienta de gestión que no es empleada por las instituciones respectivas ni la población involucrada. No se le ejecuta a través de una programación, y tampoco es incluida como parte de una política cultural a nivel local, que debería tener como actor principal al Municipio de Querétaro, aunque la elaboración de la misma estuvo a cargo de IMPLAN Querétaro. Incidiendo sobre este problema, Jiménez Guillén (2016) indica que

...la herramienta principal ya la tienen, el Plan de Manejo, solo falta implementarlo y para ello se requiere sin demora la creación de la Unidad de Gestión o su equivalente oficina
Figura 19. Plaza de la Independencia. Recuperado de http://www.wikiwand. com/es/Centro_hist\%C3\%B3rico_de_ Santiago_de_Quer\%C3\%A9taro 
del Centro Histórico. Existen programas, recursos, acciones e iniciativas que se han y están ejecutándose de manera aislada y en aparente descoordinación, obras en espacios públicos - plazas y jardines- vialidades, intervenciones en monumentos, señalética, movilidad e infraestructura. (párr. 30)

\section{Referencias}

Ejea, T. (2008). La política cultural de México en los últimos años. Casa del Tiempo, I (5-6), 2-7.

Gómez, P. F. (2013). La gestión urbana de los centros históricos. Estudios sobre Conservación, Restauración y Museología, I, 189-196.

Gonzáles, C., \& Hiernaux, D. (2015). La patrimonialización y turistificación de los centros históricos de las ciudades medias. El caso de Querétaro. Topofilia, Revista de Arquitectura, Urbanismo y Territorios, $V(1), 275-291$.

Icazurriaga, C., \& Osorio, L. (2007). La relación periferia-centro en la ciudad de Querétaro mediante las prácticas de movilidad y consumo. Alteridades, 17 (33), 21-41.

Jiménez, David. (11 de diciembre, 2016). 20 años después: Zona de Monumentos Históricos de la Ciudad de Querétaro. Diario Querétaro. Recuperado de https://www.diariodequeretaro.com. $\mathrm{mx} /$ cultura/20-anos-despues-zona-de-monumentos-historicos-de-la-ciudad-dequeretaro/

IMPLAN Querétaro. (2011). Plan de Manejo de la Zona de Monumentos Históricos de Santiago de Querétaro. Recuperado de https://issuu.com/joelperea/docs/plan_de_manejo_queretaro-mexico

Ortiz, Á., Cabrera, I., \& Hernández, J. (2013). Más que la suma de las partes: análisis del Programa Hábitat Vertiente Centros Históricos en la Ciudad de México. Perspectivas de Políticas Públicas (4), 165-187.

Reyes, J., Simoes, L., Murthino, V., Rigueiro, C., \& Gonzales, A. (2015). Ejemplificación de la problemática actual de las ciudades latinoamericanas, a través del análisis de Santiago de Querétaro. En L. Braganza, A. Naguissa Yuba, \& C. Engel de Alvarez (Eds.), Latin American and European Conference on sustainable buildings and communities (pp. 1825-1834). Guimaraes, Portugal: s.e.

Rodríguez, F. (2008). Por una política cultural de Estado en México. Casa del Tiempo, I (5-6), 16-20.

Sánchez, M. R. (7 de marzo, 2000). La rehabilitación de los centros históricos en México: Un estado de la cuestión. Biblio 3W. Revista Bibliográfica de Geografía y Ciencias Sociales, (215), 16.

Secretaría de Desarrollo Social. (2011). Guía metodológica para la formulación, seguimiento y evaluación de planes de manejo para las ciudades mexicanas Patrimonio de la Humanidad, y los centros históricos y tradicionales del país. México D. F.

Tapia, A. (2006). Turismo cultural en las ciudades mexicanas Patrimonio Mundial. Cuadernos de Patrimonio Cultural y Turismo, (14), 74-80.

Valadez, M., \& Huitrón, L. A. (2011). Balance y perspectiva de los Planes de Manejo en el INAH. Hereditas (15-16), 50-59 de Monumentos Históricos de Santiago de Querétaro, por IMPLAN Querétaro, 2011. 